\title{
Testing a Breast Cancer Prevention and a Multiple Disease Prevention Weight Loss Programme Among Women Within The UK NHS Breast Screening Programme - A Randomised Feasibility Study
}

\author{
Michelle Harvie ( $\square$ michelle.harvie@manchester.ac.uk) \\ Manchester University NHS Foundation Trust https://orcid.org/0000-0001-9761-3089 \\ David P French \\ University of Manchester \\ Mary Pegington \\ University of Manchester \\ Grace Cooper \\ Manchester University NHS Foundation Trust \\ Anthony Howell \\ University of Manchester \\ Sarah McDiarmid \\ Manchester University NHS Foundation Trust \\ Cheryl Lombardelli \\ Manchester University NHS Foundation Trust \\ Louise Donnelly \\ Manchester University NHS Foundation Trust \\ Helen Ruane \\ Manchester University NHS Foundation Trust \\ Katharine Sellers \\ Manchester University NHS Foundation Trust \\ Emma Barrett \\ Manchester University NHS Foundation Trust \\ Christopher J. Armitage \\ University of Manchester \\ D Gareth Evans \\ Manchester University Hospitals Foundation Trust
}

\section{Research}

Keywords: breast screening, breast cancer, weight loss, behaviour change, cardiovascular risk, NHS Health Check, website

Posted Date: December 17th, 2020

DOl: https://doi.org/10.21203/rs.3.rs-129135/v1

License: (c) (i) This work is licensed under a Creative Commons Attribution 4.0 International License. Read Full License 


\section{Abstract}

Excess weight and unhealthy behaviours (sedentariness, high alcohol and suboptimal diet) are common among women attending breast screening. These factors increase the risk of breast cancer and other diseases. We tested the feasibility and acceptability of a weight loss/ behaviour change programme framed to reduce breast cancer risk (breast cancer prevention programme, BCPP) compared to one framed to reduce risk of breast cancer, cardiovascular disease (CVD) and diabetes (T2D) (multiple disease prevention programme, MDPP).

\section{Methods}

Women aged 47-73 years with overweight or obesity $(n=1356)$ in the NHS Breast Screening Programme (NHSBSP) were randomized (1:2) to be invited to join a BCPP or a MDPP. The BCPP included personalised information on individual level of breast cancer risk and a web and phone weight loss/behaviour change intervention. The MDPP also included an NHS Health Check (lipids, blood pressure, HbA1c and personalised feedback for risk of CVD [QRISK2] and T2D [QDiabetes and HbA1c]). Uptake, retention, change in weight, and potential harms (anxiety and self-rated health) were assessed, along with the numbers in the MDPP with previously unknown CVD and T2D risk.

\section{Results}

The BCPP and MDPP had comparable rates of uptake; 45/508 (9\%) vs. 81/848 (10\%) 12-month retention; $33 / 45$ (73\%) vs. 53/81 (65\%) and numbers (\%) losing $\geq 5 \%$ body weight at 12 months; $26 / 45$ (58\%) vs. $46 / 81$ (57\%) with baseline observation carried forward imputation. Both groups experienced reductions in state anxiety score; BCPP ( $n=37)-0.7$ (-4.6 to 3.2), MDPP ( $n=60)-3.5$ $(-6.7$ to -0.4$)$ and an increase in the EQ-5D-5L score; BCPP $(n=40) 4.1$ (0.6 to 7.6), MDPP ( $n=60) 7.3$ (3.6 to 11.1). The MDPP identified $15 \%$ of women with a previously unknown 10 year CVD QRISK2 of $\geq 10 \%$ and $56 \%$ with 10 -year Qdiabetes risk of $\geq 10 \%$.

\section{Conclusions}

The MDPP identified previously unknown CVD and T2D risk factors but does not appear to increase engagement with behaviour change beyond a standard BCPP amongst women attending breast screening. The results suggest a definitive effectiveness trial of the BCPP intervention is warranted, with acceptable uptake and retention, and a clear weight loss signal.

\section{Trial Registration}

ISRCTN91372184, https://doi.org/10.1186/ISRCTN91372184, registered 28 September 2014.

\section{Background}

Women in the UK aged between 50 and 70 years are invited for breast screening as part of the National Health Service Breast Screening Programme (NHSBSP). Many attendees have overweight or obesity (62\%) (1), sedentariness (80\%) (1), have high alcohol intakes (11.5\%) (1), sub-optimal diets (80\%) (2) and smoke (16\%) (3). It is estimated that these factors combined may be responsible for $30 \%$ of breast cancers(4) and signficant proportions of other multifactorial consitions including $70 \%$ of $C V D(5)$, and $90 \%$ of $T 2 \mathrm{D}(6)$. Unhealthy behaviours and the associated disease risks are not currently addressed within the NHSBSP.

There are currently moves to introduce breast cancer (BC) risk assessment to the NHSBSP in order to identify higher risk women for chemoprevention and risk adapted breast screening(7) (8-10). The Predicting Risk of Cancer at Screening (PROCAS) study reported up to $21 \%$ of 57,902 in the Greater Manchester NHSBSP are at either high or above average risk of BC (10-year risk of $\geq 5 \%$ ), $50 \%$ are at average risk ( 10 -year risk of $2-4.9 \%$ ) and $29 \%$ are at low risk (10 year risk $<2 \%$ ) $(11)$.

Women of breast screening age in the UK are also eligible for assessment of CVD and T2D risk assessment as part of the NHS Health Check. Current coverage and outcomes for this programme are sub-optimal as it is mainly opportunistic (12). Recent Public Health England reports estimate that only $49 \%$ of adults with raised cholesterol and $57 \%$ with hypertension have been identified. Furthermore only $30-50 \%$ of those with raised levels currently receive appropriate statin (35\%) or anti-hypertensive (49\%) 
medications (13). Offering CVD and T2D risk assessment and a behaviour change programme at breast screening could provide systematic access to CVD and T2D care pathways due to high NHSBSP coverage and thus potentially better outcomes.

This feasibility study included women with overweight/obesity who had been previously informed of their personal risk of BC as part of the PROCAS study (1). The PROCAS study involved women aged between 46 and 73 years attending the Manchester NHSBSP (49\% of those offered study entry). This included women in the age extension trial of the NHSBSP(14) 3-years either side of the usual 50-70 age group. Women were provided with a personalised estimate of their risk of BC derived using the Tyrer-Cuzick model (version-8 which includes family history, hormonal risk factors, BMI and visually assessed mammographic density(1). ThePROCAS lifestyle study reported here aimed to explore the feasibility of BCPP and MDPP for women following receipt of BC risk estimates as part of risk stratified screening. A sample of women participating in the PROCAS study were randomised to receive an invitation to join a standard web and phone Breast Cancer Prevention Programme (BCPP) which reminded women of their personal risk of BC or a Multiple Disease Prevention Programme (MDPP) which additionally included an NHS Health Check to assess lipids, blood pressure, Hba1c, provided personalised risk feedback for CVD, T2D, and emphasised the links between health behaviours and dementia. We previously reported that higher BC risk predicted uptake retention and weight loss success across the combined BCPP and MDPP experimental conditions (Harvie et al 2019). We now report the main trial objectives which includes the feasibility, acceptability and potential efficacy for weight loss and behaviour change of the BCPP and MDPP. We also report any associated harms of the programmes, which included whether informing women they were at different levels of BC risk only (BCPP) or CVD, T2D and BC risk (MDPP), predicted lower levels of engagement, i.e. retention and weight loss success within the groups, the fidelity of delivery and engagement to the programmes and patient feedback. We report the prevalence of previously unknown CVD and T2D risk identified in the MDPP group to inform the potential of the MDPP to identify high risk individuals attending breast screening. A further aim was to determine which of these programmes should be tested further in a definitive large scale RCT within the NHSBSP.

\section{Method}

\section{Study design}

We conducted a single centre prospective two arm randomized trial (1:2) of BCPP vs MDPP amongst women attending the NHSBSP, and who had participated in the PROCAS study. Recruitment was between November 2014 and October 2015. This period was a median (range) $55(5-72)$ months after completing BC risk assessments and $6.5(0-63)$ months after receiving personalised BC risk feedback as part of the PROCAS study. The long lag between risk assessment and feedback was because of the need to validate the Tyrer-Cuzick risk assessment model among women attending the NHSBSP. All trial procedures were undertaken at the Prevent Breast Cancer Research Unit at Wythenshawe Hospital, Manchester University NHS Foundation Trust.

\section{$\underline{\text { Recruitment and randomisation }}$}

The study included women with overweight/obesity $\left(\mathrm{BMI} \geq 25 \mathrm{~kg} / \mathrm{m}^{2}\right)$ aged $47-73$ years who had been identified and informed they were at high (10-year risk $\geq 8 \%$ ), above average (5-7.9\%), average (2-4.9\%) or low-risk (<2\%) of BC as described previously (1). Women were randomised 1:2 to receive a mailed invitation to either the BCPP or MDPP programmes. Randomisation to the two different invitations allowed us to assess uptake separately to the two programmes (Fig 1). Interested women were asked to check their eligibility on the trial website, or to ring the trial office if they did not have immediate access to the internet. Women were excluded if they did not have access to a phone or the internet, had a previous diagnosis of cancer, T2D or CVD, were currently prescribed statins, had a major physical or psychiatric condition which made them unsuitable for a home based diet and physical activity (PA) programme, or were current users of HRT since weight only affects risk of BC amongst non-HRT users (15). The invitation letter included an opt-out slip to indicate reasons they were not eligible or not interested.

The sample size of 120 (40 BCPP and 80 MDPP) was pragmatic and included 10 women from each BC risk group to the BCPP and 20 from each BC risk group to the MDPP to allow us to assess uptake, retention and weight loss success across the BC risk groups. We included a larger MDPP group to assess issues that are likely to arise when patients are given this novel programme Randomisation was undertaken independently from the research team in the Department of Statistics at Manchester University NHS Foundation Trust using nQuery Advisor 7.0. The first batch used a 1:2 randomisation of BCPP to MDPP across the four BC 
risk groups. Subsequent randomisations were adaptive to the response rate of each risk category in the two groups until 45 women were randomised to the BCPP and 81 to the MDPP groups.

\section{The BCPP and MDPP programmes}

Both programmes were delivered by research dietitians who had undergone training on communicating personalised risk of BC, CVD, T2D and dementia and the lifestyle prevention of these conditions. The BCPP reminded women of their personal BC risk. The MDPP provided personal BC risk and also their personalised risk of developing CVD (10-year and lifetime risk and heart age from QRISK2 (16) and T2D (10 year risk from QDiabetes (17) and measured HbA1c).

Both programmes promoted weight loss of $\geq 5 \%$ and communicated how weight loss reduces disease risk as a gain-framed message to increase response efficacy(18). The BCPP group received generic advice that weight loss of $\geq 5 \%$ and adherence to PA and alcohol recommendations could lead to significant reductions in risk of BC (25\%)(19;20), T2D (60\%)(21) and CVD (30\%)(22). The MDPP group were provided personalised estimates of changes in CVD risk from predicted reductions in blood pressure and total cholesterol from published literature (i.e. a $1 \mathrm{~mm} / \mathrm{Hg}$ reduction in systolic blood pressure per $1 \%$ weight loss up to a $10 \%$ weight loss(23) and a $1 \%$ reduction in total cholesterol for every $1 \%$ weight loss up to a 15\% weight loss)(24). Changes in T2D risk were estimated by entering the target reduced weight in the QDiabetes tool. Results of the NHS Health Check were sent to the patient's family doctor to allow appropriate follow up and clinical management, e.g. checking abnormal results and consideration of medications for raised cholesterol, blood pressure and $\mathrm{HbA} 1 \mathrm{c}$.

Both programmes included individual face-to-face diet and PA advice for women to follow either a daily or intermittent (5:2) energy restricted Mediterranean diet which we have found to be effective in our previous weight loss studies(25). Women were also advised to meet PA recommendations (i.e. at least 150 minutes of moderate intensity or the equivalent amount of vigorous activity as well as 40 minutes of resistance exercise per week)(26). Suitability to follow a home based PA programme was confirmed using the adult pre-physical activity screening system tool (27), with family doctor clearance where necessary. PA advice was tailored to each patient's preferences, abilities and co-morbidities, with referral to local services where appropriate. Women were asked to limit alcohol intake to $<10$ units/week and smoking cessation was discussed where appropriate. Those reporting high-risk alcohol intakes with Alcohol Use Disorders Identification Test (AUDIT) scores >8 (28) or who were currently smoking were encouraged to access local NHS alcohol and smoking cessation services and their family doctor was informed.

Both programmes were supported by a trial website which encouraged women to self-monitor and record their weight, diet (completion of restricted days in the 5:2 diet and actual food and drink intake) and cardiovascular and resistance exercise. It hosted weekly menu plans, recipes, information about BC, CVD, T2D and dementia, tips for planning and managing emotional eating, online videos of the recommended resistance and stretching exercises (Physiotec, Canada) and a monthly newsletter to maintain engagement. Women received tailored feedback on their self-reported behaviours from their allocated trial dietitian in scheduled phone calls (weeks 1, 4, 8) and weekly personalised e-mails for 6-months. Between 6 and 12-months women received automated monthly emails in response to website entries. These e-mails gave positive feedback for records showing weight loss or weight maintenance, or encouraged re-engagement with the programmes if weight had increased by $\geq 1 \mathrm{~kg}$ or if no website entries had been recorded.

Communicating personalised risk information without increasing self-efficacy or encouraging self-regulation is not likely to produce changes in behaviour(29). Given this, both programmes included key behaviour change techniques as recommended in the UK NICE behaviour change guidance, including goal setting, planning, relapse prevention, self-monitoring, and encouraging individuals to identify sources of social support for changing behaviours(30).

\section{$\underline{\text { Outcome measures }}$}

\section{Uptake and retention}

For each programme we recorded the number of women who were invited and consented to join the study, and who were not interested or not eligible to take part and the reasons for this. Also retention to the programmes at 3, 6 and 12 months.

Health-related behaviour change and weight loss 
We assessed change in weight and body fat (Tanita MC-180MA,Tanita Europe, Amsterdam, The Netherlands), self-reported PA (IPAQ)(31), alcohol harms and intake (AUDIT (28) and 7-day food diary), saturated fat intake (7-day food diary) (32) and current smoking in both groups.

\section{Potential harms of the programmes}

Potential harms of both programmes were assessed in terms of changes in perceived self-rated anxiety (state trait anxiety)(33) and health status (EQ-5D-5L)(34). Within the MDPP we assessed whether being identified at different levels of CVD and T2D disease risk was associated with disengagement from behaviour change, evidenced by any differences in withdrawal and degree of weight loss.

Previously unidentified CVD and T2D risk in the MDPP group

We assessed the prevalence of previously unknown raised CVD and T2D risk identified in the MDPP programme. Also the numbers referred to NHS behaviour change services (i.e. exercise on referral, alcohol and smoking cessation services) or commenced on statins or blood pressure medications.

\section{Fidelity of delivery and engagement to the programmes}

We assessed the numbers of scheduled calls and e-mails received, engagement with the web site and the amount of dietitian time that was used to deliver the programmes.

\section{Patient feedback}

We collated anonymised 12-month patient questionnaires which rated satisfaction with the overall programme, study visits and the trial website. This included free text suggestions for how the programmes could be improved. A specific website feedback questionnaire was completed at 3 and 6 months to include feedback from women who might leave the programme before 12 months.

\section{Analysis}

Descriptive statistics of uptake and retention and changes in weight and health behaviours in the MDPP and BCPP groups were undertaken. Baseline observation carried forward (BOCF) values are reported for changes in weight (\% and kg), body fat (kg), alcohol intake and PA, and a completers only analysis for state anxiety and self-rated health status. We also undertook exploratory formal statistics to assess comparisons of changes in these parameters relative to baseline between the BCPP and MDPP conditions. The findings of these are reported with the caveat there is multiple testing of secondary outcomes and the study is not necessarily powered to show differences.

Within the MDPP group, multivariable logistic regression was used to assess the association between estimated level of CVD and T2D risk and the likelihood of withdrawal at 12 months. This was assessed in terms of 10-year CVD QRISK2, heart age compared to actual age or having a first degree relative with CVD, 10-year QDiabetes and having a first degree relative with diabetes. A priori confounding variables included; BC risk (high, above average, average and low), index of multiple deprivation (IMD quintiles ; 1, 2 and 3-5)(35), smoking status (never, ex-smoker and current smoker), age and BMI at baseline.

Within the MDPP group linear mixed-effects models were used to assess the percentage of weight loss from baseline over time in low and high CVD and T2D risk categories using all available baseline 3, 6 and 12-month weight data. The best-fitting variancecovariance structure was based on information criterion, and nested models were compared using likelihood ratio test. Each specific CVD and T2D risk category (low vs high) was treated as a fixed-effect, and time as a continuous covariate. Time was also included as a random-effect, allowing the rate of weight loss to differ between patients. Polynomial factors of time were tested as both fixed and random effects to see if their inclusion improved model fit. The confounding variables used in the withdrawal analysis were included as fixed effects, and comparisons made between the coefficients of the risk variables before and after adjustment. $\mathrm{P}<0.05$ was considered statistically significant for all analysis. All statistical analyses were conducted using SPSS version 23 (IBM Corp, Armonk NY, USA), R version 3.5.1 and Stata Statistical Software: Release 16.) 


\section{Results}

Recruitment and retention to the programmes

Uptake to the study was comparable with invitations to both the BCPP and MDPP (45/508 9\%; vs. 81/848, 10\% p=0.7) (Figure 2). An additional 57 women invited to the BCPP (11\%) and 135 invited to the MDPP (16\%) were interested in join but were not eligible. This was mainly due to existing health problems such as previous CVD, cancer and raised cholesterol (7.1\% BCPP, 12.0\% MDPP). Other reasons for declining included lack of internet access (1.4\% BCPP, 0.8\% MDPP) and current use of HRT (1.0 \% BCPP, $1.2 \%$ MDPP). A further 8 women invited to the BCPP $(2 \%)$ and 7 invited to the MDPP (1\%) wished to enter the study but responded after recruitment was complete. An additional 130 women (10\%) invited to both programmes returned a response slip to say they were not interested to take part. The most common reasons cited were lack of time (28\%), issues travelling to the centre for trial appointments $(18 \%)$, family illness or caring duties (12\%). Uptake to both programmes was greater in women at high and above average $\mathrm{BC}$ risk compared to average and low risk as reported previously (Table 1) (36).

Five women in the BCPP $(11 \%)$ and 16 women in the MDPP (20\%) left the programme during the 6 months of phone and e-mail dietitian support (Figure 2). A further 6 BCPP (14\%) and 12 MDPP (15\%) women left the programme during the automated e-mail support period between 6 and 12 months. Of the total women who left the programmes in the 12-month period, i.e. 11 (25\%) in the BCPP and 28 (35\%) in the MDPP groups, 7 BCPP (16\%) and 20 MDPP (25\%) asked to withdraw and a further 4 BCPP (9\%) and 8 MDPP (10\%) lost contact. The most commonly cited reasons for withdrawal included personal or family illness $(n=11,43 \%)$, too busy $(n=5,17 \%)$, and not able to adhere to the programme $(n=5,17 \%)$ (Figure 2$)$.

Baseline characteristics of participants are reported in Table 2. The BCPP and MDPP groups were comparable. Women were mainly from the three least deprived quintiles of the index of multiple deprivation and were white British. Approximately one third of the cohort had a family history of BC (BCPP $26.7 \%$ MDPP $34.6 \%$,). Sixty-two percent of the BCPP and $60.5 \%$ MDPP groups had previously undertaken a commercial weight loss programme, whilst there were few smokers (BCPP 6.7\% vs MDPP 7.4\%).

\section{Efficacy of the programmes for weight loss and behaviour change}

Both programmes achieved good and comparable reductions in weight and body fat and health behaviours (Table 3). Mean (95\% Cl) BOCF percentage weight loss at 12-months were -7.6 (-9.8 to -5.4$) \%$ in the BCPP group and $-7.4(-9.1$ to -5.7$) \%$ in the MDPP group ( $\mathrm{p}=0.952)$. BOCF weight loss at 12-months was $-6.01(-7.87$ to -4.1$) \mathrm{kg}$ in the BCPP group and $-6.2(-7.8$ to -4.71$) \mathrm{kg}$ in the MDPP group ( $p=0.673)$, with respectively $58 \%$ and $57 \%$ and achieving weight loss of $\geq 5 \%(P=0.915)$.

The proportion reporting at risk drinking (AUDIT score $\geq 8$ ) reduced from $8(17.5 \%)$ in the BCPP and $22(27.2 \%)$ in the MDPP at baseline to respectively $4(8.9 \%)$ and $14(17.3 \%)$ at 6 months. Likewise the proportion of women reporting saturated fat intakes above the recommended intake of $20 \mathrm{~g} /$ day reduced from $29(87.9 \%)$ in the BCPP and $40(72.7 \%)$ in the MDPP at baseline to respectively $12(36.4 \%)$ and $19(34.5 \%)$ at 6 months. Both groups also reported modest increases in moderate intensity PA at 6 months. One woman from each group had stopped smoking by 6 months and were stillnot smoking at the 12-month follow up.

\section{Adverse events and harms associated with the programmes}

No study or intervention related adverse events occurred. Completer-only analysis showed a small reductions in state anxiety score with the BCPP ( $n=37)-0.7$ (-4.6 to 3.2) and MDPP ( $n=60)-3.5(-6.7$ to -0.4$)$, and an increase in EQ-5D-5L scores in the BCPP $(n=40) 4.1$ (0.6 to 7.6) and MDPP groups $(n=60) 7.3$ (3.6 to 11.1) (Table 3). The proportion reporting a high state anxiety score $(\geq 40)$ at baseline was $6(16.2 \%)$ BCPP and 18 (30\%) MDPP compared to 7 (18.9\%) BCPP and 15 (25\%) MDPP and at 6-months.

\section{Does level of disease risk predict retention and weight loss success in the BCPP \& MDPP?}

Retention and weight loss success appeared to be greater amongst women at higher risk BC risk in the BCPP group, but were more variable across $\mathrm{BC}$ risk categories for the MDPP group (Table 1).

Within the MDPP, women informed they had a higher CVD QRISK2 score at baseline were more likely to leave the programme. Adjusted odds ratio for leaving $(95 \% \mathrm{Cl}) 1.36(1.08,1.80)$ for each unit increase in 10 year CVD QRISK2 score $(p=0.02)$ and 1.22 
$(1.03,1.46)$ for each year of predicted heart age greater than their actual age $(p=0.02)$. However, neither weight loss success nor rate of weight loss differed according to level of estimated CVD or T2D risk (Table 5 and Figure 3 ).

Graphs for the predicted probabilities of percentage weight loss over time from the mixed-effects models. These contained the baseline level of CVD and T2D risk predictor, time, time ${ }^{2}$ and predictor $x$ time interactions as fixed effects, as well as patient-level random effects adjusting for the confounding variables and confounder $x$ time interactions which had been found to be significant at $\mathrm{P}<0.1$ (Table 5).

NHS Health Check results in the Multiple Disease Prevention Programme

Ten women (12.3\%) in the MDPP group had previously had an NHS Health Check that had been undertaken more than 6 months prior to joining the study. Relatively high numbers of women in the MDPP group had previously unknown increased risks for CVD ( $14.8 \%$ with $\geq 10 \% 10$ year risks of CVD and $14.8 \%$ with total cholesterol $\geq 7.5 \mathrm{mmol} / \mathrm{L}$ ) and for T2D (56\% with $\geq 10 \% 10$-year risk of T2D, and $6.2 \%$ with $\mathrm{HbA} 1 \mathrm{c}$ (Table 3). Some of these women were subsequently commenced on medications for blood pressure $(n=2)$ and raised cholesterol $(n=1)$ by their family doctor.

\section{Fidelity of programme delivery}

The initial face-to-face consultation with the research dietitian included personalised risk for just BC (BCPP) or BC, CVD and T2D (MDPP) and diet and PA advice for both groups. On average these took 40 minutes for the BCPP group and 60 minutes for the MDPP group.

Across both groups, women received $90 \%$ of their scheduled week 1,4 and 8 calls and $95 \%$ of their scheduled e-mails. Mean (range) duration of calls was 21 ( 6 to 50 ) minutes and mean ( range) time taken for staff to prepare and send e-mails was 15 ( 5 to 30) minutes. There was good engagement with the self-monitoring website. Ninety-seven percent of women used the website at least once in the first 3 months, 87\% 3-6 months, 83\% 6-9 months and 79\% 9-12 months. Twenty-seven percent of women received an automated e-mail between 6 and 12 months to alert them they had recorded weight gain of $\geq 1 \mathrm{~kg}$. $\mathrm{Mean}(95 \% \mathrm{Cl})$ number of website entries over the 12-month period was 89 (76-102) entries per woman. Ninety-nine percent of women opted to follow the $5: 2$ diet at baseline with respectively $82.5 \%$ and $58 \%$ still following this diet at 3 and 6 months. A number of women in the BCPP and MDPP groups were referred to NHS behaviour change services; PA referral services 8 (18\%) BCPP and 23 (28.4\%) MDPP, smoking cessation 1 out of 3 smokers BCPP and 5 out of 6 smokers MDPP, and alcohol services 0 BCPP and 4 (4.9\%) MDPP by their allocated dietitian.

\section{Participant feedback}

Anonymous satisfaction questionnaires for the overall programme were completed by $71 / 88$ (81\%) of those who completed the study at 12 months (26,57\% of the BCPP group and $45,55 \%$ of the MDPP group). Of these, the numbers who were very or extremely satisfied (ranked $8 / 10$ to $10 / 10$ ) with different elements of the programmes were as follows: diet advice and meal plans 53/71 (75\%), PA advice and plans 36/71 (51\%), telephone reviews 68/71 (96\%), weekly individualised e-mails 69/71 (97\%), and automated e-mails during 6- 12 months 51/71 (72\%). For the MDPP group only, satisfaction with the NHS Health Check assessments was 44/45 (96\%) and communication of their personalized CVD and T2D risk was 45/45(100\%).

Website evaluation was completed by $109 / 126$ (87\%) of women. Ninety-two (73\%) patients agreed or strongly agreed the website was easy to use, and 92 (73\%) felt confident to use the website. Thus, the phone and e-mail feedback was well received. Women understood and positively evaluated the CVD and T2D risk feedback and dietary elements of the programme. However, they were less confident to follow the PA plans.

Free text feedback showed that women felt their self-efficacy to undertake PA would increase with a demonstration class or DVD. They emphasised the need for review calls to be scheduled, and that feedback e-mail should be personalised and not generic. They valued the advice from the dietitian who was considered a credible source of information. A number of changes to the website were suggested including a forum to facilitate peer-to-peer communication and support, an 'ask the expert' function, and

Page $7 / 21$ 
adding an average weight loss line to their weight tracker so they could compare their weight loss with the average of the other participants.

\section{Discussion}

\section{Main finding $\underline{s}$}

The BCPP and MDPP appear feasible with good uptake, retention weight loss success and fidelity. Both programmes produced mean weight loss at 12 months of over $6 \mathrm{~kg}(7 \%)$. The MDPP highlighted previous unknown risk of CVD and T2D but does not appear to increase engagement with behaviour change beyond a standard BCPP amongst women attending breast screening. There was no evidence of harms in terms of self-rated anxiety or poorer health status with either programme.

Overall uptakes to the mailed invitation to both programmes was around $10 \%$. This is comparable to previously reported uptakes to behaviour change programmes when written invitations are given to women when they attend the NHSBSP, or when postal invitations are sent to women at increased risk of $\mathrm{BC}$ (37). This feasibility study highlights potential strategies to increase recruitment to weight loss programmes within the NHSBSP. Firstly, focussing on women at high or above average BC risk who had uptakes of $14-20 \%$ compared to $4-10 \%$ for women at average or low BC risk reported herein and previously within this cohort(36). Higher risk women will also derive a greater absolute risk reduction from changes in health behaviours compared to low risk women. $(38 ; 39)$

Future programmes could include women with existing health conditions. Significant proportions of women who were interested to join the programmes were ineligible due to pre-existing weight related health conditions (7.1 BDPP and 12\% of the MDPP group). We presume these weight related health conditions were not currently being addressed within existing NHS weight loss/behaviour change services. Inclusion of these women would have given uptakes of and 18.1 to the BCPP and $23.0 \%$ to the MDPP. Lastly, recruiting women at their mammogram appointments and using remote collection of outcome measures such as weight would overcome identified barriers of time and travel around additional appointments reported by women who declined to join this study.

Both programmes appear highly effective for weight loss and behaviour change. The mean weight loss at 12 months over $6 \mathrm{~kg}$ using baseline carried forward imputation compares favourably with outcomes from group-based commercial (2-4kg), internet $(1.9 \mathrm{~kg})$, and primary care programmes $(0.7-3.6 \mathrm{~kg}) .(40)$

There was good engagement with the website and phone supported programmes. This hybrid face-to-face and remotely delivered programme allowed women to receive initial individual face-to-face advice from a health care professional combined with the website that allows self-monitoring and prompt regular feedback from the health care professional. Such programmes have been found to be both more and less effective compared to standard face-to-face programmes, dependent on the level of user engagement achieved(41).

Most previous website programmes have been tested amongst younger cohorts. The few studies amongst older women concur with our findings of good engagement (42-44), and the potential for their utility amongst women of breast screening age. The 2018 Office of National Statistics bulletin reported large increases in internet usage amongst older women. In 2018, 98\% of women aged 44-54 years had used the internet in the past 3 months, compared to $92 \%$ of $55-64$ year olds(45) and $80 \%$ of $65-74$ year olds.

Further patient involvement and engagement (PPIE) work can help refine the invitation and recruitment strategy to the programmes. This could include a personalised letter of endorsement of the trial from their family doctor (46). PPIE work is specifically required to promote uptake amongst women from black, Asian, minority ethnic and socially deprived groups who had low uptakes to this study, as seen with previous breast screening and cancer trials (47). Other potential strategies, such as face-toface introduction to the trial at the time of screening and telephone follow up after the mailed invite(48) are unlikely to be feasible due to the size of the target population. 
There has been minimal research on the feasibility or efficacy of multiple disease prevention programmes. It was thought that multiple disease risk information could be personally relevant to a larger group of women than just providing risk information on a single disease such as $B C$, increasing the likelihood of having a positive effect on behaviours(49). Alternatively, it was possible multiple disease risk information could reduce motivation and self-efficacy and threaten self-integrity to change health behaviours in some individuals. We found no difference in engagement and behaviour change with a supervised MDPP compared to the BCPP.

There was no evidence of harm with the MDPP such as increased anxiety, or lower self-rated health assessed with the EQ-5D as a result of being provided with personalised risk of CVD and T2D. This is an important finding which is in line with other studies of providing risk information, despite concerns about adverse effects(50) (51). The higher drop out in women at higher baseline risk of CVD in the MDPP group may be an incidental finding. CVD risk information by itself has minimal effect on health behaviours(52). In the recent INFORM trial neither genotypic or phenotypic coronary heart disease risk information influenced the efficacy of a web based lifestyle programme for changes in PA, diet or weight (53). The mixed effects models in our current study showed comparable weight loss success according to level of CVD; however, these models were based on small numbers and assumed that data was missing at random. Future studies should assess whether CVD risk information impacts on engagement and the efficacy of weight loss programmes.

\section{Strengths and weakness}

This is one of the few studies to test the feasibility and acceptability of a BC prevention and multiple disease prevention programmes in women in the breast screening programme. Also, one of the few to test website and phone programmes amongst middle - aged women. Twelve-month data including 6 months of website-only support provides an indication of the long term effects of the programmes for weight loss maintenance.

Key limitat19ions that a future effectiveness trial should address are as follows. The study invited a selected group of women who had previously been recruited to the PROCAS study, who were recruited sometime after their attendance at breast screening. Studies need to test uptake to the programmes in an unselected cohort at the time of breast screening. In addition, all trial procedures were conducted at a research unit. Future effectiveness studies should ideally be in a screening site or a nearby community location to inform how these programmes could be integrated within the NHSBSP or be totally remote or online. Secondary trial end-points (e.g. weight) were assessed by members of the research team which sometimes included the research dietitians delivering the intervention who were not blinded to the intervention. The study included two intervention groups and did not include a no intervention control group which would be required in a definitive randomised trial.

$\underline{\text { Implications and Future research }}$

We set out to test the feasibility and acceptability of a BCPP or MDPP amongst women in the breast screening programme and whether there were any additional benefits with the MDPP programme. Hence which programme was worthy of further investigation in a large scale RCT within the NHSBSP. Both programmes met the NICE criteria for the efficacy of weight loss programmes, i.e. at least $60 \%$ of partcipants are likely to complete, average weight loss is at least $3 \%$, and at least $30 \%$ of partcipants lose $\geq 5 \%$ of their initial weight(54). The simpler lower cost BCPP would be the preferred test programme to assess long-term behaviour change and weight loss and reduced risk of BC vs standard care and other weight and health behaviour related conditions.

Increased coverage and appropriate medication are current targets for the NHS Health Check programme (13). Given this, future trials could assess the impact of offering a MDPP around the time of breast screening to increase coverage of CVD and T2D risk assessment and whether a one-stop shop can increase NHS efficiency and potential uptake to the NHS BSP.

Dietitians delivered the test programmes. Future programmes could consider provision of original dietary advice by a dietitian as a trusted source of knowledge, with ongoing support from a health trainer to reduce costs. This model of delivery has been favourably evaluated in other weight loss settings (55) and likely to be more effective than programmes which are entirely delivered by non-specialists which have achieved only modest weight loss (56). Further work is required to improve the PA component of the programme which had modest effects on PA. 


\section{Conclusion}

The MDPP identified previously unknown CVD and T2D risk factors but does not appear to increase engagement with behaviour change beyond a standard BCPP amongst women attending breast screening. The results suggest a definitive effectiveness trial of the BCPP intervention is warranted. Weight loss achieved with a BCPP will reduce risk of BC as well as CVD and T2D and other weight related cancers and health conditions.

\section{Abbreviations}

BC Breast cancer

CVD Cardiovascular disease

T2D Type 2 diabetes

NHSBSP NHS Breast Screening Programme

BMI Body mass index

BOCF Baseline observation carried forward

PROCAS Predicting of Cancer at Screening

BCPP Breast cancer prevention programme

MDPP Multiple disease prevention programme

\section{Declarations}

\section{Acknowledgements}

DGE, MH, MP, DPF, CJA and AH are supported by the NIHR Manchester Biomedical Research Centre (IS-BRC-1215-20007). CJA is supported by NIHR Greater Manchester Patient Safety Translational Research Centre.

Ethics approval and consent to participate

The study was approved by the NRES Committee West Midlands-Solihull, reference 14/WM/1088. Informed written consent was obtained from all subjects and the study was perfomed in accordance with the Declaration of Helsinki.

Consent for publication

Not applicable.

Availability of data and materials

The trial protocol and all datasets used and analysed during the current study are available from the corresponding author on reasonable request.

Competing interests

The authors declare that they have no competing interests.

\section{Funding}

This project was funded by Prevent Breast Cancer (registered charity number 1109839) and supported by the NIHR Manchester Biomedical Research Centre (IS-BRC-1215-20007). The funders had no role in the design, conduct, analysis or write up of the study. 
Authors' contributions

Conception: MH, DF, AH, LD, DGE, CJA. Data collection: MP, GC, SM, CB, HR, and KS. Data analysis: MH, MP, GC, EB. Manuscript writing: $M H, M P, D F, G C, S M, A H, L D, H R, D G E$. All authors read and approved the final manuscript.

Acknowledgements

We acknowledge the work of David Preece for set up and management of the trial website, Sarah Sampson, Paula Stavrinos, Jake Southworth (Manchester University NHS Foundation Trust) for help with recruitment, Julie Pickford, Alison Morgan (Public Health Manchester), Basil Issa, Ed Gambol, Joyce Yeo (Manchester University NHS Foundation Trust), Christi Deaton (University of Cambridge) for their advice and support for assessing and communicating CVD, T2D and dementia risk, the Prevent Breast Cancer patient Public Involvement panel for their advice and invaluable insights.

\section{References}

1. Evans DG, Astley S, Stavrinos P, Harkness E, Donnelly LS, Dawe S, et al. Improvement in risk prediction, early detection and prevention of breast cancer in the NHS Breast Screening Programme and family history clinics: a dual cohort study. NIHR Journals Library; 2016 Aug.

2. Public Health England and the Food Standards Agency. National Diet and Nutrition Survey Results from Years 7 and 8 (combined) of the Rolling Programme (2014/2015 to 2015/2016). 2018 https://www.gov.uk/government/statistics/ndnsresults-from-years-7-and-8-combined Accessed 17.11.20

3. Green J, Reeves GK, Floud S, Barnes I, Cairns BJ, Gathani T, et al. Cohort Profile: the Million Women Study. Int J Epidemiol 2018 Jun 4.

4. Arthur R, Wassertheil-Smoller S, Manson JE, Luo J, Snetselaar L, Hastert T, et al. The Combined Association of Modifiable Risk Factors with Breast Cancer Risk in the Women's Health Initiative. Cancer Prev Res (Phila) 2018 Jun;11(6):317-26.

5. Chomistek AK, Chiuve SE, Eliassen AH, Mukamal KJ, Willett WC, Rimm EB. Healthy lifestyle in the primordial prevention of cardiovascular disease among young women. J Am Coll Cardiol 2015 Jan 6;65(1):43-51.

6. Hu FB, Manson JE, Stampfer MJ, Colditz G, Liu S, Solomon CG, et al. Diet, lifestyle, and the risk of type 2 diabetes mellitus in women. N Engl J Med 2001 Sep 13;345(11):790-7.

7. Shieh Y, Eklund M, Madlensky L, Sawyer SD, Thompson CK, Stover FA, et al. Breast Cancer Screening in the Precision Medicine Era: Risk-Based Screening in a Population-Based Trial. J Natl Cancer Inst 2017 Jan;109(5).

8. Evans DG, Donnelly LS, Harkness EF, Astley SM, Stavrinos P, Dawe S, et al. Breast cancer risk feedback to women in the UK NHS breast screening population. Br J Cancer 2016 Apr 26;114(9):1045-52.

9. Mango V, Bryce Y, Morris EA, Gianotti E, Pinker K. Commentary ACOG Practice Bulletin July 2017: Breast Cancer Risk Assessment and Screening in Average-Risk Women. Br J Radiol 2018 Oct;91(1090):20170907.

10. French DP, Astley S, Brentnall AR, Cuzick J, Dobrashian R, Duffy SW, et al. What are the benefits and harms of risk stratified screening as part of the NHS breast screening Programme? Study protocol for a multi-site non-randomised comparison of BC-predict versus usual screening (NCT04359420). BMC Cancer 2020 Jun 18;20(1):570.

11. van Veen EM, Brentnall AR, Byers H, Harkness EF, Astley SM, Sampson S, et al. Use of Single-Nucleotide Polymorphisms and Mammographic Density Plus Classic Risk Factors for Breast Cancer Risk Prediction. JAMA Oncol 2018 Apr 1;4(4):476-82.

12. Patel R, Barnard S, Thompson K, Lagord C, Clegg E, Worrall R, et al. Evaluation of the uptake and delivery of the NHS Health Check programme in England, using primary care data from 9.5 million people: a cross-sectional study. BMJ Open 2020 Nov 5;10(11):e042963.

13. Public Health England. Health Matters: Preventing Cardiovascular Disease.

https://www.gov.uk/government/publications/health-matters-preventing-cardiovascular-2019 Accesed $17^{\text {th }}$ November 2020

14. NHS Breast Screening Programme. AgeX Trial. http//www.agex.uk AgeX Trial 2020 Accesed 17.11.20

15. World Cancer Research Fund. Diet ,nutrition, physical activity and breast cancer2018

https://www.wcrf.org/sites/default/files/Breast-cancer-report.pdf. Accesed 17.11.20

Page 11/21 
16. University of Nottingham and EMIS. Q Risk. 2018. https://www.emishealth.com/news-events/news/qrisk2-now-available-asopen-source-software/ Accessed 10.5.2018

17. Hippisley-Cox J, Coupland C. Development and validation of QDiabetes-2018 risk prediction algorithm to estimate future risk of type 2 diabetes: cohort study. BMJ 2017 Nov 20;359:j5019.

18. O'Keefe DJ, Jensen JD. The relative persuasiveness of gain-framed and loss-framed messages for encouraging disease prevention behaviors: a meta-analytic review. J Health Commun 2007 Oct;12(7):623-44.

19. Harvie M, Howell A, Vierkant RA, Kumar N, Cerhan JR, Kelemen LE, et al. Association of gain and loss of weight before and after menopause with risk of postmenopausal breast cancer in the lowa women's health study. Cancer Epidemiol Biomarkers Prev 2005 Mar;14(3):656-61.

20. Catsburg C, Miller AB, Rohan TE. Adherence to cancer prevention guidelines and risk of breast cancer. Int J Cancer 2014 Apr 10.

21. Knowler WC, Fowler SE, Hamman RF, Christophi CA, Hoffman HJ, Brenneman AT, et al. 10-year follow-up of diabetes incidence and weight loss in the Diabetes Prevention Program Outcomes Study. Lancet 2009 Nov 14;374(9702):1677-86.

22. Ebrahim S, Taylor F, Ward K, Beswick A, Burke M, Davey SG. Multiple risk factor interventions for primary prevention of coronary heart disease. Cochrane Database Syst Rev 2011 Jan 19;(1):CD001561.

23. Jarrett RJ, Keen H, Murrells T. Changes in blood pressure and body weight over ten years in men selected for glucose intolerance. J Epidemiol Community Health 1987 Jun;41(2):145-51.

24. Aucott L, Gray D, Rothnie H, Thapa M, Waweru C. Effects of lifestyle interventions and long-term weight loss on lipid outcomes - a systematic review. Obes Rev 2011 May;12(5):e412-e425.

25. Harvie M, Wright C, Pegington M, McMullan D, Mitchell E, Martin B, et al. The effect of intermittent energy and carbohydrate restriction v. daily energy restriction on weight loss and metabolic disease risk markers in overweight women. Br J Nutr 2013 Oct; 110(8):1534-47.

26. UK Department of Health. Start Active, Stay Active: A report on physical activity for health from the four home countries' Chief Medical Officers. 2011. https://sportengland-production-files.s3.eu-west-2.amazonaws.com/s3fs-public/dh_128210.pdf. Accessed 10.5.2018

27. Professor Kevin Norton, Dr Lynda Norton. Pre-exercise Screening: Guide to the Australian adult pre-exercise screening system. ISBN 978-0-646-56771-6, 2011.

28. Dawson DA, Grant BF, Stinson FS, Zhou Y. Effectiveness of the derived Alcohol Use Disorders Identification Test (AUDIT-C) in screening for alcohol use disorders and risk drinking in the US general population. Alcohol Clin Exp Res 2005 May;29(5):84454.

29. French DP, Cameron E, Benton JS, Deaton C, Harvie M. Can Communicating Personalised Disease Risk Promote Healthy Behaviour Change? A Systematic Review of Systematic Reviews. Ann Behav Med 2017 Mar 13.

30. National Institute for Health and Care Excellence (NICE). Behaviour change: Individual approaches. NICE 2014 https://www.nice.org.uk/guidance/ph49/resources/behaviour-change-individual-approaches-pdf-1996366337989 Accessed $\underline{28.12 .2018}$

31. International Physical Activity Questionnaire (IPAQ) long version. Karolinska Institutet 2014 www.ipaq.ki.se. Accessed 28.12 .2018

32. NIHR Cambridge Biomedical Research Centre. DAPA measurement toolkit. NIHR Cambridge Biomedical Research Centre 2020 https://dapa-toolkit.mrc.ac.uk/diet/subjective-methods/estimated-food-diaries Accessed 25.09.2020

33. Marteau TM, Bekker $\mathrm{H}$. The development of a six-item short-form of the state scale of the Spielberger State-Trait Anxiety Inventory (STAI). Br J Clin Psychol 1992 Sep;31 ( Pt 3):301-6.

34. Janssen MF, Pickard AS, Golicki D, Gudex C, Niewada M, Scalone L, et al. Measurement properties of the EQ-5D-5L compared to the EQ-5D-3L across eight patient groups: a multi-country study. Qual Life Res 2013 Sep;22(7):1717-27.

35. Department for Communities and Local Government. The English Indices of Deprivation 2010. Department for Communities and Local Government 2011 
https://assets.publishing.service.gov.uk/government/uploads/system/uploads/attachment_data/file/6320/1870718.pdf Accessed 9.08.2020

36. Harvie M, Pegington M, French D, Cooper G, McDiarmid S, Howell A, et al. Breast cancer risk status influences uptake, retention and efficacy of a weight loss programme amongst breast cancer screening attendees: two randomised controlled feasibility trials. BMC Cancer 2019 Dec 4;19(1):1089.

37. Evans DG, Harvie M, Bundred N, Howell A. Uptake of breast cancer prevention and screening trials. J Med Genet 2010 Dec;47(12):853-5.

38. Hopper JL, Dite GS, MacInnis RJ, Liao Y, Zeinomar N, Knight JA, et al. Age-specific breast cancer risk by body mass index and familial risk: prospective family study cohort (ProF-SC). Breast Cancer Res 2018 Nov 3;20(1):132.

39. Maas P, Barrdahl M, Joshi AD, Auer PL, Gaudet MM, Milne RL, et al. Breast Cancer Risk From Modifiable and Nonmodifiable Risk Factors Among White Women in the United States. JAMA Oncol 2016 Oct 1;2(10):1295-302.

40. Hartmann-Boyce J, Johns DJ, Jebb SA, Summerbell C, Aveyard P. Behavioural weight management programmes for adults assessed by trials conducted in everyday contexts: systematic review and meta-analysis. Obes Rev 2014 Nov;15(11):920-32.

41. Sorgente A, Pietrabissa G, Manzoni GM, Re F, Simpson S, Perona S, et al. Web-Based Interventions for Weight Loss or Weight Loss Maintenance in Overweight and Obese People: A Systematic Review of Systematic Reviews. J Med Internet Res 2017 Jun 26;19(6):e229.

42. O'Brien T, Jenkins C, Amella E, Mueller M, Moore M, Hathaway D. An Internet-Assisted Weight Loss Intervention for Older Overweight and Obese Rural Women: A Feasibility Study. Comput Inform Nurs 2016 Nov;34(11):513-9.

43. Pullen $\mathrm{CH}$, Hageman PA, Boeckner L, Walker SN, Oberdorfer MK. Feasibility of Internet-delivered weight loss interventions among rural women ages 50-69. J Geriatr Phys Ther 2008;31(3):105-12.

44. van der Mark M, Jonasson J, Svensson M, Linne Y, Rossner S, Lagerros YT. Older members perform better in an internet-based behavioral weight loss program compared to younger members. Obes Facts 2009;2(2):74-9.

45. Office of National Statistics. Internet users, UK: 2018. https://www.ons.gov.uk/businessindustryandtrade/itandinternetindustry/bulletins/internetusers/2018\#older-adults-are-lesslikely-to-use-the-internet Accessed 10.09.2020

46. Crocker JC, Ricci-Cabello I, Parker A, Hirst JA, Chant A, Petit-Zeman S, et al. Impact of patient and public involvement on enrolment and retention in clinical trials: systematic review and meta-analysis. BMJ 2018 Nov 28;363:k4738.

47. Evans DG, Brentnall AR, Harvie M, Astley S, Harkness EF, Stavrinos P, et al. Breast cancer risk in a screening cohort of Asian and white British/Irish women from Manchester UK. BMC Public Health 2018 Jan 25;18(1):178.

48. Treweek S, Pitkethly M, Cook J, Fraser C, Mitchell E, Sullivan F, et al. Strategies to improve recruitment to randomised trials. Cochrane Database Syst Rev 2018 Feb 22;2:MR000013.

49. Cooke R, Sheeran P. Moderation of cognition-intention and cognition-behaviour relations: a meta-analysis of properties of variables from the theory of planned behaviour. Br J Soc Psychol 2004 Jun;43(Pt 2):159-86.

50. Marteau TM, Kinmonth AL, Thompson S, Pyke S. The psychological impact of cardiovascular screening and intervention in primary care: a problem of false reassurance? British Family Heart Study Group. Br J Gen Pract 1996 Oct;46(411):577-82.

51. French DP, Southworth J, Howell A, Harvie M, Stavrinos P, Watterson D, et al. Psychological impact of providing women with personalised 10-year breast cancer risk estimates. Br J Cancer 2018 May 8.

52. Sheridan SL, Viera AJ, Krantz MJ, Ice CL, Steinman LE, Peters KE, et al. The effect of giving global coronary risk information to adults: a systematic review. Arch Intern Med 2010 Feb 8;170(3):230-9.

53. Silarova B, Sharp S, Usher-Smith JA, Lucas J, Payne RA, Shefer G, et al. Effect of communicating phenotypic and genetic risk of coronary heart disease alongside web-based lifestyle advice: the INFORM Randomised Controlled Trial. Heart 2019 Jul;105(13):982-9.

54. NICE. Weight management: lifestyle services for overweight or obese adults. NICE 2014 https://www.nice.org.uk/guidance/PH53 Accessed 2.11.2018

55. Zizzi S, Kadushin P, Michel J, Abildso C. Client Experiences With Dietary, Exercise, and Behavioral Services in a CommunityBased Weight Management Program. Health Promot Pract 2016 Jan;17(1):98-106. 
56. Nanchahal K, Power T, Holdsworth E, Hession M, Sorhaindo A, Griffiths U, et al. A pragmatic randomised controlled trial in primary care of the Camden Weight Loss (CAMWEL) programme. BMJ Open 2012;2(3).

\section{Tables}

Table 1. Uptake retention and weight loss within the BCPP and MDPP groups across breast cancer risk categories

\begin{tabular}{|c|c|c|c|c|c|c|c|c|c|c|}
\hline & BCPP & & & & & MDPP & & & & \\
\hline $\begin{array}{l}\text { 10-year risk } \\
\text { of breast } \\
\text { cancer }\end{array}$ & $\begin{array}{l}\text { Invited } \\
\text { n }\end{array}$ & $\begin{array}{l}\text { Uptake } \\
\text { n (\%) }\end{array}$ & $\begin{array}{l}\text { Retention } \\
\text { at } 12 \\
\text { months } \mathrm{n} \\
(\%)\end{array}$ & $\begin{array}{l}\text { Weight } \\
\text { loss } \\
\%^{a}\end{array}$ & $\begin{array}{l}\% \\
\text { Losing } \\
\geq 5 \% \\
\text { weight } \\
\mathrm{n}(\%)\end{array}$ & $\begin{array}{l}\text { Invited } \\
\text { n }\end{array}$ & $\begin{array}{l}\text { Uptake } \\
\text { n (\%) }\end{array}$ & $\begin{array}{l}\text { Retention } \\
\text { at } 12 \\
\text { months n } \\
(\%)\end{array}$ & $\begin{array}{l}\text { Weight } \\
\text { loss }\end{array}$ & $\begin{array}{l}\% \\
\text { Losing } \\
\geq 5 \% \\
\text { weight n } \\
\text { (\%) }\end{array}$ \\
\hline Low $(<2 \%)$ & 206 & $8(3.9)$ & $3(37.5)$ & $\begin{array}{l}-4.2 \\
(-9.7 \\
\text { to+1.3) }\end{array}$ & $2(25)$ & 354 & $20(5.6)$ & $12(60)$ & $\begin{array}{l}-6.8 . \\
(-10.6 \\
\text { to } \\
-3.0)\end{array}$ & $\begin{array}{l}10 \\
(50.0)\end{array}$ \\
\hline $\begin{array}{l}\text { Average } \\
(<5 \text { to }>2 \%)\end{array}$ & 171 & $17(9.9)$ & $13(76.5)$ & $\begin{array}{l}-7.0 \\
(-11.1 \\
\text { to }-3.0)\end{array}$ & $\begin{array}{l}10 \\
(58.8)\end{array}$ & 267 & $21(7.9 \%)$ & $16(76)$ & $\begin{array}{l}-7.1 \\
(-10.1 \\
\text { to } \\
-4.2)\end{array}$ & $12(57.1)$ \\
\hline $\begin{array}{l}\text { Above } \\
\text { average } \\
(\geq 5<8 \%)\end{array}$ & 59 & $\begin{array}{l}10 \\
(16.9)\end{array}$ & $9(90.0)$ & $\begin{array}{l}-9.3 \\
(-15.0 \\
\text { to }-3.6)\end{array}$ & $6(60)$ & 127 & $20(16)$ & $11(55)$ & $\begin{array}{l}-7.3 \\
(-11.1 \\
\text { to } \\
-3.4)\end{array}$ & $\begin{array}{l}11 \\
(55.0)\end{array}$ \\
\hline High ( $\geq 8 \%)$ & 72 & $\begin{array}{l}10 \\
(13.9)\end{array}$ & $8(80.0)$ & $\begin{array}{l}-9.6 \\
(-14.6 \\
\text { to }-4.5)\end{array}$ & $8(80)$ & 100 & $20(20)$ & $14(70)$ & $\begin{array}{l}-8.4 \\
(-12.4 \\
\text { to } \\
-4.4)\end{array}$ & $13(65.0)$ \\
\hline Total/average & 1356 & $45(8.9)$ & $33(73.3)$ & $\begin{array}{l}-7.6 \\
(-9.8 \text { to } \\
-5.4)\end{array}$ & $\begin{array}{l}26 \\
(58)\end{array}$ & 738 & $81(9.6)$ & $53(65.4)$ & $\begin{array}{l}-7.4 \\
(-9.1 \text { to } \\
-5.7)\end{array}$ & $\begin{array}{l}46 \\
(56.8)\end{array}$ \\
\hline
\end{tabular}

a mean ( $95 \%$ confidence interval) baseline carried forward percentage weight loss at 12 months

Table 2. Baseline characteristics of the BCPP and MDPP groups 


\begin{tabular}{|c|c|c|}
\hline & $\begin{array}{l}\text { ВСРP } \\
(n=45)\end{array}$ & $\begin{array}{l}\text { MDPP } \\
(\mathrm{n}=81)\end{array}$ \\
\hline \multirow[t]{2}{*}{ Age (years) ${ }^{a}$} & $59.1(4.8)$ & $60.3(5.4)$ \\
\hline & $51.7-73.7$ & $51.2-72.0$ \\
\hline \multirow[t]{2}{*}{$\operatorname{BMI}\left(\mathrm{kg} / \mathrm{m}^{2}\right)^{a}$} & $31.1(4.8)$ & $31.6(4.4)$ \\
\hline & $25.6-46.9$ & $25.0-43.8$ \\
\hline Overweight ${ }^{\mathrm{b}}$ & $23(51.1)$ & 37 (45.7) \\
\hline Obese $^{b}$ & $22(48.9)$ & $44(54.3)$ \\
\hline \multicolumn{3}{|l|}{ Townsend quintile $\mathrm{b}$ : } \\
\hline 1 (least deprived) & $12(26.7)$ & $28(34.6)$ \\
\hline 2 & $21(46.7)$ & $31(38.3)$ \\
\hline 3 & $9(20)$ & $16(19.8)$ \\
\hline 4 & $3(6.7)$ & $4(4.9)$ \\
\hline 5 (most deprived) & $0(0)$ & $2(2.5)$ \\
\hline First degree relative with breast cancer ${ }^{b}$ & $12(26.7)$ & $28(34.6)$ \\
\hline Pre, peri/postmenopausal ${ }^{b}$ & 7 (15.6)/ 38 (84.4) & $9(11.1) / 72(88.9)$ \\
\hline Current smoker ${ }^{\text {b }}$ & $3(6.7)$ & $6(7.4)$ \\
\hline \multicolumn{3}{|l|}{ Ethnicity b: } \\
\hline White British & $42(93.3)$ & $80(98.8)$ \\
\hline Asian & $2(4.4)$ & 0 \\
\hline Afro-Caribbean & $1(2.2)$ & $1(1.2)$ \\
\hline \multirow[t]{2}{*}{ Time since receiving breast cancer risk feedback (months) ${ }^{a}$} & $11.6(15.6)$ & $13.2(13.7)$ \\
\hline & $1-63$ & $1-54$ \\
\hline Previous commercial weight loss programme ${ }^{b}$ & $28(62.2)$ & $49(60.5)$ \\
\hline Previous primary care weight loss service ${ }^{b}$ & $2(4.4)$ & $4(4.9)$ \\
\hline
\end{tabular}

a mean (SD) minimum - maximum

${ }^{b} \mathrm{n}(\%)$

Table 3. Previously unknown cardiovascular and diabetes risk markers and estimated risks at baseline in the MDPP 


\begin{tabular}{|lllllll|}
\hline \multicolumn{3}{|l}{ Cardiovascular Risk } & & & \multicolumn{2}{l|}{ Type-2 Diabetes Risk } \\
\hline $\begin{array}{l}\text { Breast cancer risk } \\
\text { categories }\end{array}$ & $\begin{array}{l}10 \text { year } \\
\text { risk } \geq 10\end{array} \%$ & $\begin{array}{l}\text { Lifetime } \\
\text { risk } \geq 25 \%\end{array}$ & $\begin{array}{l}\text { Total cholesterol } \\
>7.5 \mathrm{mmol} / \mathrm{L}\end{array}$ & $\begin{array}{l}\text { Systolic blood } \\
\text { pressure }>140 \mathrm{mmHg}\end{array}$ & $\begin{array}{l}10 \text { year } \\
\text { risk } \geq 10 \\
\%\end{array}$ & $\begin{array}{l}\mathrm{HbA} 1 \mathrm{c}>42 \\
\mathrm{mmol} / \mathrm{mmol}\end{array}$ \\
\hline $\begin{array}{l}\text { High/moderately } \\
\text { increased }(\mathrm{n}=40)\end{array}$ & $8(20.0)$ & $20(50.0)$ & $7(17.5)$ & $19(47.5)$ & $23(57.5)$ & $1(2.5)$ \\
\hline $\begin{array}{l}\text { Average/below } \\
\text { average }(\mathrm{n}=41)\end{array}$ & $4(10.0)$ & $16(39.0)$ & $5(12.2)$ & $21(51.2)$ & $22(53.7)$ & $4(9.8)$ \\
\hline Total $(\mathrm{n}=81)$ & $12(14.8)$ & $36(44.4)$ & $12(14.8)$ & $40(49.4)$ & $45(55.6)$ & $5(6.2)$ \\
\hline
\end{tabular}

$\mathrm{N}(\%)$ 


\begin{tabular}{|c|c|c|c|c|c|c|}
\hline & \multirow{2}{*}{\multicolumn{3}{|c|}{$\begin{array}{l}\text { Breast cancer prevention } \\
\text { programme } \\
\mathrm{N}=45\end{array}$}} & \multicolumn{3}{|c|}{$\begin{array}{l}\text { Multiple disease prevention } \\
\text { programme }\end{array}$} \\
\hline & & & & \multicolumn{3}{|l|}{$N=81$} \\
\hline & Baseline & $\begin{array}{l}6 \\
\text { months }\end{array}$ & $\begin{array}{l}12 \\
\text { months }\end{array}$ & Baseline & 6 months & $\begin{array}{l}12 \\
\text { months }\end{array}$ \\
\hline \multirow[t]{2}{*}{ Weight $(\mathrm{kg})^{\mathrm{a}^{*}}$} & 82.4 & 76.7 & 77.2 & 83.7 & 76.8 & 77.0 \\
\hline & $\begin{array}{l}(78.3- \\
86.4)\end{array}$ & $\begin{array}{l}(75.4- \\
77.8)\end{array}$ & $\begin{array}{l}(75.3- \\
79.2)\end{array}$ & $\begin{array}{l}(80.8- \\
86.8)\end{array}$ & $\begin{array}{l}(75.2- \\
78.4)\end{array}$ & $\begin{array}{l}(75.6- \\
78.5)\end{array}$ \\
\hline$\geq 5 \%$ weight loss $\mathrm{a}^{\star \star}$ & & $31(69)$ & $26(58)$ & & $55(68)$ & $46(57)$ \\
\hline \multirow[t]{2}{*}{ Body fat $(\mathrm{kg})^{a^{*}}$} & 33.3 & 28.6 & 29.1 & 34.4 & 29.6 & 29.8 \\
\hline & $\begin{array}{l}(30.4 \\
-36.1)\end{array}$ & $\begin{array}{l}(25.2- \\
32.0)\end{array}$ & $\begin{array}{l}(25.8- \\
32.3)\end{array}$ & $\begin{array}{l}(32.5- \\
36.3)\end{array}$ & )$^{(27.6-31.6}$ & $\begin{array}{l}(27.6- \\
31.8)\end{array}$ \\
\hline \multirow{2}{*}{$\begin{array}{l}\text { Minutes of moderate physical activity / day } \\
(\text { (IPAQ) })^{a^{*}}\end{array}$} & 117 & 126 & N/A & 110 & 117 & N/A \\
\hline & $(99-136)$ & $\begin{array}{l}(108- \\
143)\end{array}$ & & $(96-124)$ & $(105-130)$ & \\
\hline \multirow{2}{*}{$\begin{array}{l}\text { Alcohol intake } \\
(\mathrm{g} / \text { week) })^{\mathrm{a}^{\star \star \star}} ¥\end{array}$} & 88.2 & 25.6 & N/A & 93.0 & 29.4 & N/A \\
\hline & $(0-175)$ & $(0-62)$ & & $(18-93)$ & $(0-90)$ & \\
\hline Alcohol & $4(3-7)$ & $3(2-5)$ & N/A & $5(3-8)$ & $4(3-7)$ & N/A \\
\hline \multicolumn{7}{|l|}{ AUDIT score $\mathrm{a}^{\star^{\star \star \star}}$} \\
\hline AUDIT score $\geq 8^{a^{\star *}}$ & $8(17.8)$ & $4(8.9 \%)$ & N/A & $22(27.2)$ & $14(17.3 \%)$ & N/A \\
\hline \multirow{2}{*}{$\begin{array}{l}\text { Saturated fat } \\
\text { (g/day) }{ }^{a^{*}} ¥\end{array}$} & 28.5 & 19.0 & N/A & 25.9 & 18.4 & N/A \\
\hline & $\begin{array}{l}(25.4- \\
31.7)\end{array}$ & $\begin{array}{l}(16.8- \\
21.1)\end{array}$ & & $\begin{array}{l}(23.6- \\
28.1)\end{array}$ & $\begin{array}{l}(16.5- \\
20.2)\end{array}$ & \\
\hline Saturated fat $>20 \mathrm{~g} /$ day ${ }^{a^{\star \star}}$ & $29(87.9 \%)$ & $\begin{array}{l}12 \\
(36.4 \%)\end{array}$ & N/A & $40(72.7)$ & $19(34.5)$ & N/A \\
\hline \multirow[t]{2}{*}{ State train anxiety ${ }^{b^{*}}$} & 30.3 & 28.0 & N/A & 33.5 & 29.8 & N/A \\
\hline & $\begin{array}{l}(25.9- \\
34.6)\end{array}$ & $\begin{array}{l}(24.1- \\
31.9)\end{array}$ & & $\begin{array}{l}(29.9- \\
37.1)\end{array}$ & $\begin{array}{l}(26.4- \\
33.3)\end{array}$ & \\
\hline \multirow{2}{*}{$\begin{array}{l}\text { State trait anxiety } \\
\geq 40^{\star \star}\end{array}$} & $6(16.2)$ & 7 (18.9) & N/A & $18(30 \%)$ & $15(25 \%)$ & N/A \\
\hline & & & & & & \\
\hline \multirow[t]{2}{*}{ EQ59-VAS ${ }^{b *}$} & 79.6 & 83.7 & N/A & 78.4 & 86.0 & $\mathrm{~N} / \mathrm{A}$ \\
\hline & $\begin{array}{l}(75.1- \\
84.1)\end{array}$ & $\begin{array}{l}(79.8- \\
87.6)\end{array}$ & & $\begin{array}{l}(74.6- \\
82.2)\end{array}$ & $\begin{array}{l}(82.6- \\
89.3)\end{array}$ & \\
\hline
\end{tabular}

a Baseline observation carried forward ${ }^{b}$ Completers only BCPP $n=37 \operatorname{MDPP} n=60$

$*$ Mean $(95 \% \mathrm{Cl}) * *$ n $(\%) * * *$ Median $\left(25^{\text {th }}\right.$ and $75^{\text {th }}$ centile $) \mathrm{N} / \mathrm{A}=$ not available

$¥$ Food diaries were completed by 33 (73\%) of the BCPP and 55 (68\%) of the MDPP groups at baseline. 
Table 5. Multivariable logistic regression of the association between baseline risk of type 2 diabetes and cardiovascular disease and withdrawal and percentage weight loss within the multiple disease prevention group $(n=81)$

\begin{tabular}{|c|c|c|c|c|c|c|c|c|}
\hline & \multicolumn{4}{|c|}{ Withdrawal from the study } & \multicolumn{4}{|c|}{$\begin{array}{l}\text { Percentage weight loss during the } 12 \\
\text { month programme }\end{array}$} \\
\hline & \multicolumn{2}{|l|}{ Unadjusted } & \multicolumn{2}{|l|}{ Adjusted* } & \multicolumn{2}{|l|}{ Unadjusted } & \multicolumn{2}{|l|}{ Adjusted* } \\
\hline & OR $(95 \% \mathrm{Cl})$ & $\begin{array}{l}P \\
\text { value }\end{array}$ & $\begin{array}{l}\text { OR } \\
(95 \% \mathrm{Cl})\end{array}$ & $\begin{array}{l}\mathrm{P} \\
\text { value }\end{array}$ & OR $(95 \% \mathrm{Cl})$ & $\begin{array}{l}P \\
\text { value }\end{array}$ & OR $(95 \% \mathrm{Cl})$ & $\begin{array}{l}\mathrm{P} \\
\text { value }\end{array}$ \\
\hline \multirow[t]{2}{*}{ Diabetes: QDiabetes } & \multirow[t]{2}{*}{$1.05(1-1.1)$} & \multirow[t]{2}{*}{0.05} & \multirow{2}{*}{$\begin{array}{l}1.03 \\
(0.94,1.11)\end{array}$} & \multirow[t]{2}{*}{0.53} & -0.076 & \multirow[t]{2}{*}{0.66} & -0.32 & \multirow[t]{2}{*}{0.20} \\
\hline & & & & & $\begin{array}{l}(-0.41 \\
0.26)\end{array}$ & & $(-0.81,0.17)$ & \\
\hline \multirow{2}{*}{$\begin{array}{l}\text { First degree relative with } \\
\text { Diabetes: No vs Yes }\end{array}$} & \multirow{2}{*}{$\begin{array}{l}1.46(0.52- \\
4.04)\end{array}$} & \multirow[t]{2}{*}{0.47} & \multirow{2}{*}{$\begin{array}{l}1.25 \\
(0.33,4.71)\end{array}$} & \multirow[t]{2}{*}{0.74} & -0.072 & \multirow[t]{2}{*}{0.71} & -0.08 & \multirow[t]{2}{*}{0.71} \\
\hline & & & & & $(-0.45,0.3)$ & & $\begin{array}{l}(-0.49 \\
0.33\end{array}$ & \\
\hline \multirow[t]{2}{*}{ CVD: QRISK2 } & \multirow{2}{*}{$\begin{array}{l}1.08(0.97- \\
1.2)\end{array}$} & \multirow[t]{2}{*}{0.17} & \multirow{2}{*}{$\begin{array}{l}1.36 \\
(1.08,1.8)\end{array}$} & \multirow[t]{2}{*}{0.02} & -0.016 & \multirow[t]{2}{*}{0.93} & -0.12 & \multirow[t]{2}{*}{0.56} \\
\hline & & & & & $\begin{array}{l}(-0.36 \\
, 0.33)\end{array}$ & & $(-0.54,0.29)$ & \\
\hline \multirow{2}{*}{$\begin{array}{l}\text { First degree relative with CVD: } \\
\text { No vs Yes }\end{array}$} & \multirow{2}{*}{$\begin{array}{l}2.26(0.81- \\
7.03)\end{array}$} & \multirow[t]{2}{*}{0.13} & \multirow{2}{*}{$\begin{array}{l}1.62 \\
(0.44,6.47)\end{array}$} & \multirow[t]{2}{*}{0.47} & -0.072 & \multirow[t]{2}{*}{0.69} & -0.01 & \multirow[t]{2}{*}{0.95} \\
\hline & & & & & $(-0.43,0.28)$ & & $(-0.42,0.39)$ & \\
\hline \multirow{2}{*}{$\begin{array}{l}\text { CVD risk: Heart age vs actual } \\
\text { age }\end{array}$} & \multirow{2}{*}{$\begin{array}{l}1.19(1.07- \\
1.35)\end{array}$} & \multirow[t]{2}{*}{0.003} & \multirow{2}{*}{$\begin{array}{l}1.22 \\
(1.03,1.46)\end{array}$} & 0.02 & -0.068 & 0.69 & +0.2 & 0.70 \\
\hline & & & & & $(-0.4,0.27)$ & & & \\
\hline
\end{tabular}

*Adjusting for age, Townsend deprivation, smoking status, BMI and breast cancer risk category

\section{Figures}



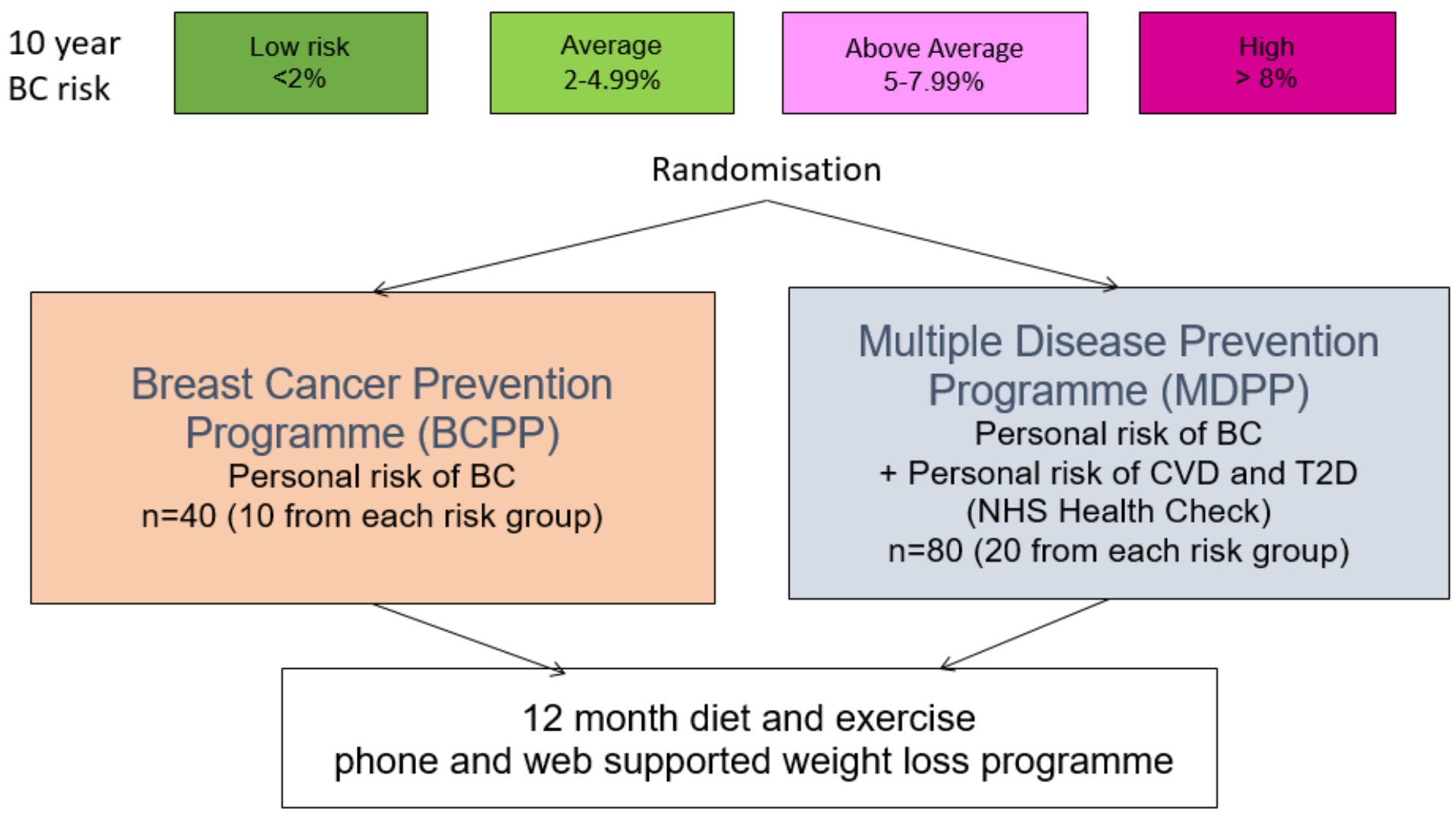

Figure 1

Study Design

10 year

$\mathrm{BC}$ risk
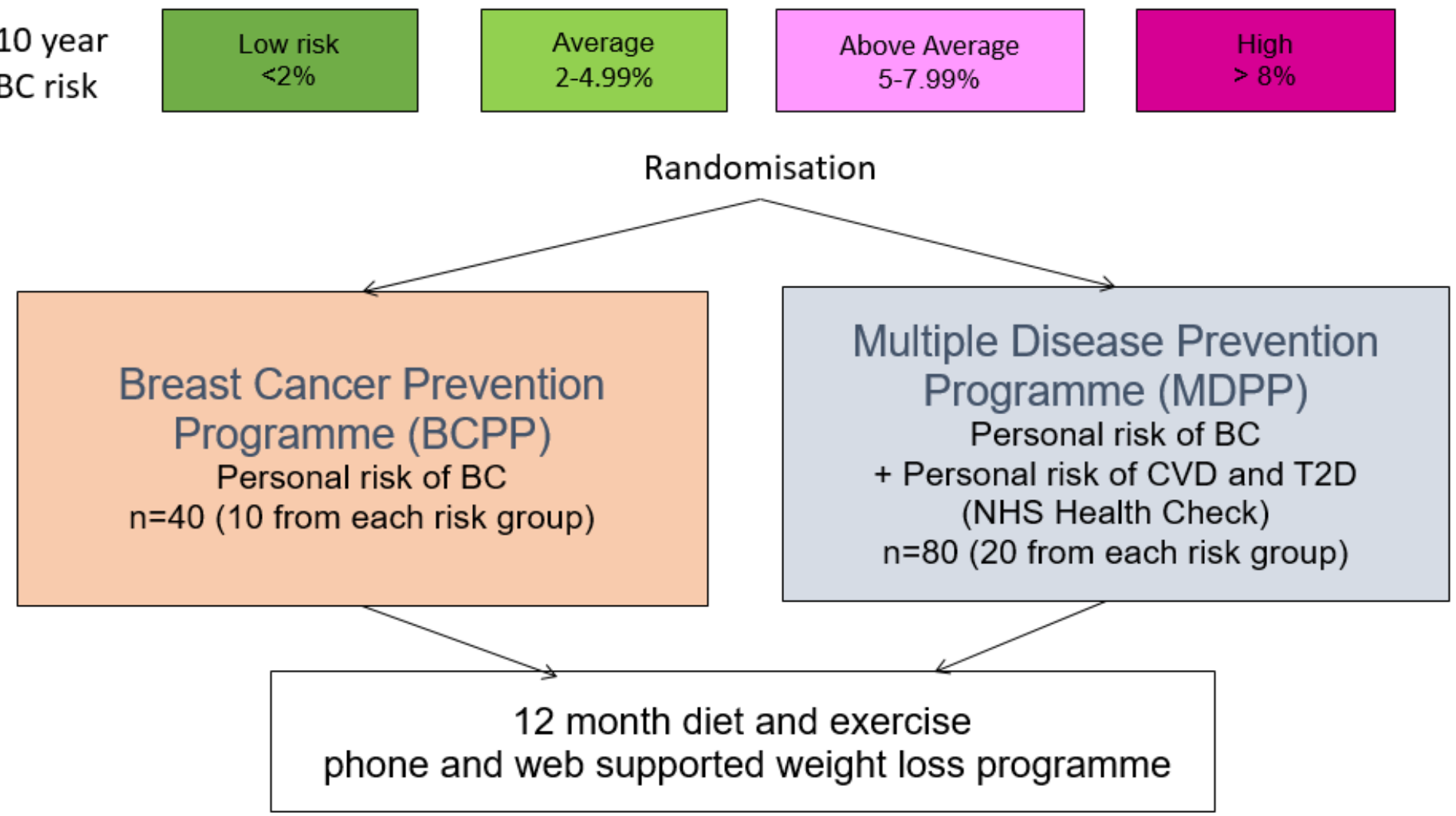

Figure 1 


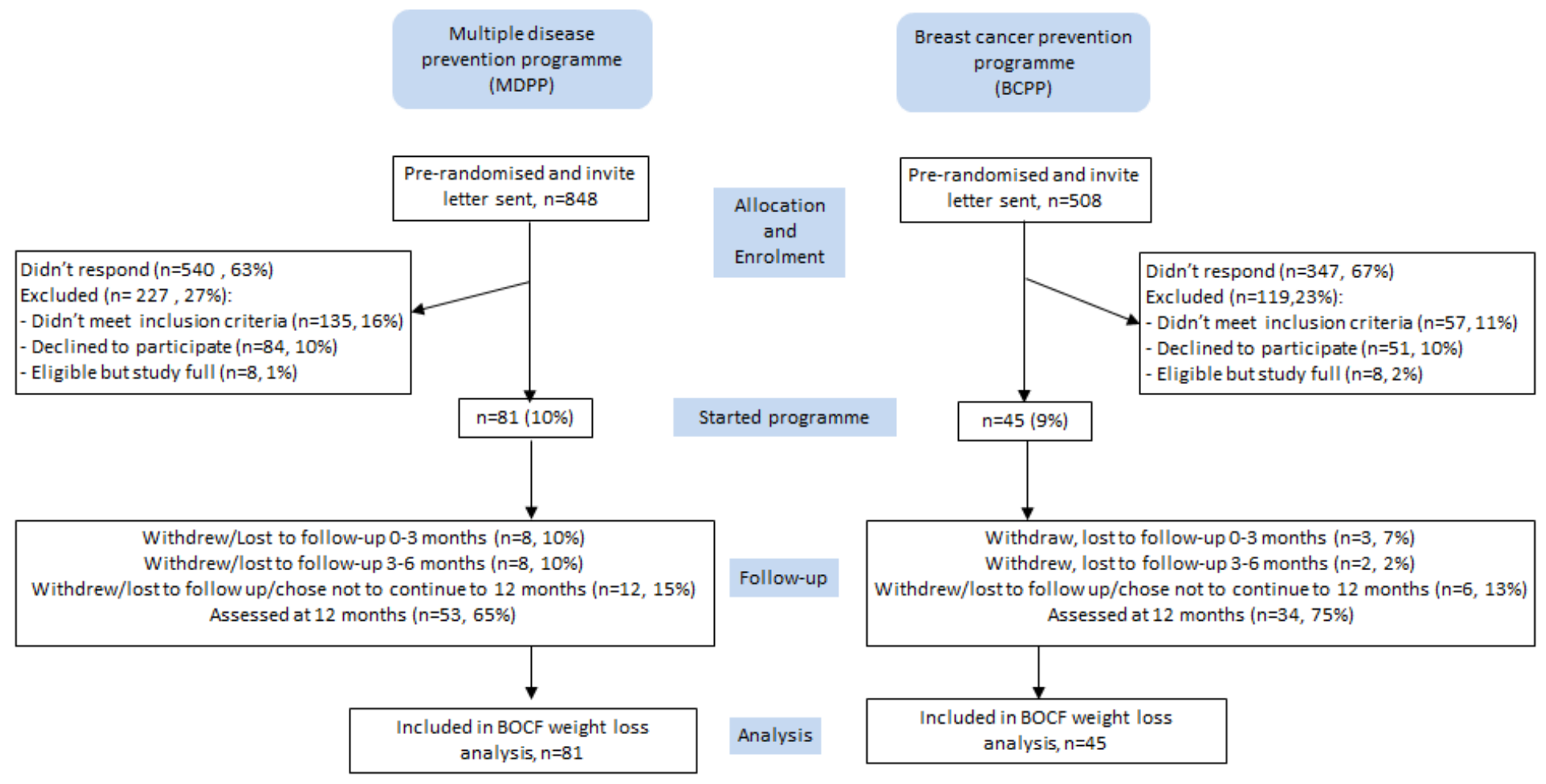

Figure 2

Consolidated Standards of Reporting Trials (CONSORT) flow diagram of patients recruited to the PROCAS lifestyle trial 

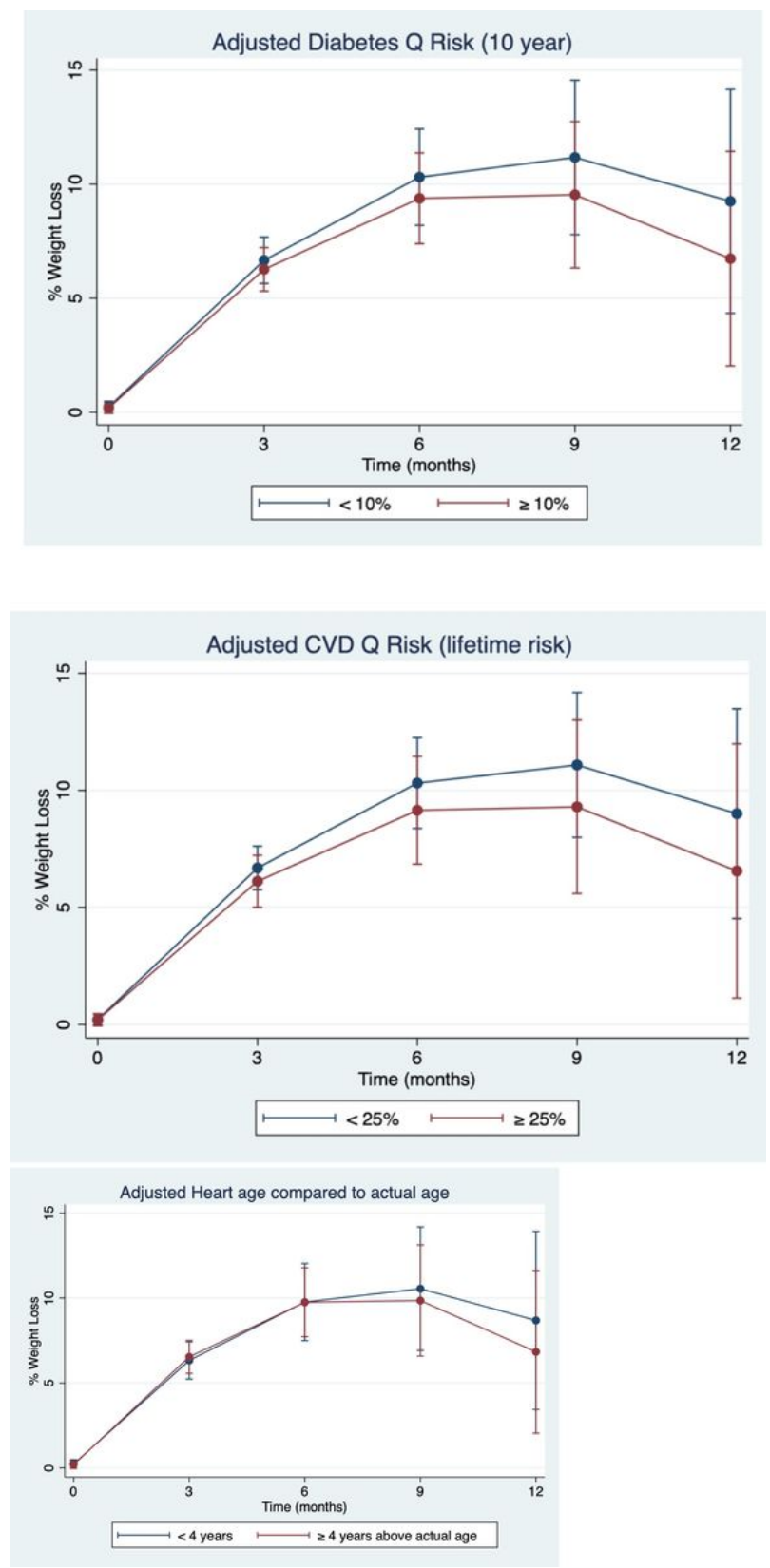

\section{Figure 3}

Probabilities of percentage weight loss over time amongst women in the MDPP group identified as above and below median levels of estimated risk of CVD and T2D

\section{Supplementary Files}

This is a list of supplementary files associated with this preprint. Click to download.

- CONSORTprocaslifestylefeasibilitystud710.12.20.doc 